\title{
Power Quality Monitoring using PMU
}

\author{
Surender Kumar* \\ DCRUST, Murthal
}

\author{
M.K. Soni \\ Manav Rachna International \\ University, Faridabad
}

\author{
D.K. Jain \\ DCRUST, Murthal \\ Sonepat
}

\begin{abstract}
Voltage sags are the most common power quality disturbance usually associated with power system faults, which can cause huge economic loss, making it the focus of emerging research. The proposed voltage sag detection technique for a singleline-to-ground (SLG) fault is presented using the PMU measurement data for improving the power quality. Various voltage sag detection techniques have been discussed to detect voltage sags. This technique detects the voltage magnitudes, frequency, rate of change of frequency and phase angle jump of voltage for a single-line-to-ground (SLG) fault.
\end{abstract}

\section{General Terms}

Power quality monitoring

\section{Keywords}

power quality, voltage sag detection, single-line-to-ground fault, phase angle jump, PMU.

\section{INTRODUCTION}

Power quality is an emerging issue that has become important to consumers at all levels of usage. Modern equipments such as microprocessor, microcontroller, programmable logic controller, and diagnostic systems, etc, are much more sensitive to power quality variations in short duration than the equipment applied in the past, are now commonly used in both the industrial/commercial sectors and the domestic environment, cause many power quality problems[1].

Power quality problems mainly include short duration power disturbances. Power quality problems have occurred in power system due to nonlinear loads, unsymmetrical load and faults. Some power quality disturbances come from the power supply network whereas others are produced by the load itself. Various surveys indicate that customers cause $80 \%$ of their own power quality problems [2].

There are two types of power quality problems i.e. power quality variations, and power quality events. The power quality variations are small deviation from the normal or desired voltage or current waveform, can be continuously measured at predetermined instances wherever events are large disturbances, occur in general unpredictable and require a trigger action to be measured. The most common origin of variations are voltage frequency variations, voltage magnitude variations; unbalance, voltage fluctuations or flicker and waveform distortion, and most common origin of events are interruptions, voltage sags, and transients.

Among various power quality events, voltage disturbances are more concerned by the engineers and researchers. It is well known that voltage sag, swell and short duration interruption are the power quality event. The voltage sag is one of the most serious power quality problems.

IEEE standard [3] defines voltage sags as a reduction in voltage for a short time. The duration of voltage sag is less than 1 minute but more than 8 milliseconds ( 0.5 cycles). The magnitude of the reduction is between 10 percent and 90 percent of the normal root mean square (rms) voltage at 50/60 Hz. IEC standard[4] defines voltage sag as voltage dip as "a temporary reduction of the voltage at a point in the electrical system below a threshold". The two terms are considered interchangeable. Fig.1. shows a voltage sag waveform.

There are various causes of voltage sags in a power system. Utilities and end users can cause voltage sags on transmission and distribution systems. A brief review of the causes of voltage sags is presented in [5].

Voltage sag usually caused $70 \%-90 \%$ power quality problems. Voltage sag, despite being a short duration event can cause serious consequences. A voltage sag affects the operation of end-users' power electronics equipments. The power electronic equipments often trips or shuts down when voltage sag occurs. Thus, voltage sag brings the greatest financial loss compared with most other types of power disturbances [6].

Therefore it is very necessary to detect voltage sag for the power quality monitoring, which is useful for improving the power system.

Further, the paper is organized as follows: Section II presents the types of sag, the overview of the existing methods of sag detection are discussed in Section III, PMU based voltage sag detection technique is presented in IV section, followed by conclusion in section $\mathrm{V}$.

\section{TYPES OF VOLTAGE SAG}

Voltage sag is basically classified as balanced or unbalanced sag and depending on sag magnitude severity can be classified as deep and shallow sag. A voltage can be either symmetrical or unsymmetrical, depending on the causes. If the individual phase voltages are equal and the phase relationship is $120^{\circ}$, the sag is symmetrical; otherwise, unsymmetrical sag. A three-phase short circuit or a large motor starting can produce symmetrical sags. Single line-to-ground, phase-to-phase, or two phase-to-ground faults due to lightning, animals, accidents, and other causes, as well as energizing of large transformers can cause unsymmetrical sags [7].

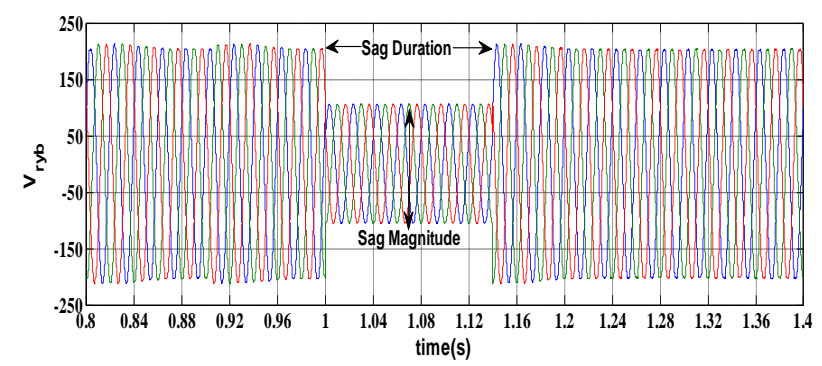

Fig. 1. Voltage sag waveform 
According to [3], the voltage sag can be classified into three types according to duration as shown in Table 1 .

Table.1. Classification of voltage sags

\begin{tabular}{|c|c|c|}
\hline Event & $\begin{array}{c}\text { Duration of } \\
\text { occurrence }\end{array}$ & Magnitude \\
\hline Instantaneous Sag & $0.5-30$ cycles & $0.1-0.9 \mathrm{pu}$ \\
\hline Momentary Sag & 30 cycles-3 s & $0.1-0.9 \mathrm{pu}$ \\
\hline Temporary Sag & $3 \mathrm{~s}-1 \mathrm{~min}$ & $0.1-0.9 \mathrm{pu}$ \\
\hline
\end{tabular}

The voltage sag has been classified into seven groups, i.e. type A, B, C, D, E, F, and G. The type A is balanced sag due a three-phase fault. This type of voltage sag is the most severe. The voltage sag of type B is due to a single phase to ground fault, which turns into type $\mathrm{D}$ after removal of the zero sequence voltage. Phase to phase fault results in a type $\mathrm{C}$. The voltage sags of type $\mathrm{E}, \mathrm{F}$ and $\mathrm{G}$ are due to a two phase to ground fault [1-5]. In this paper single phase to ground fault of three- phase power supply (type B) is considered.

\section{Characterizing Features of Voltage Sag}

The main characterising features of voltage sag are its magnitude, duration and phase-angle jump [7].

The magnitude of a voltage sag: It can be defined as the rms value of the voltage during the fault. Also, sag magnitude may be defined as the amplitude of the voltage drop, leading to an opposite meaning, as shown in fig. 3.

The magnitude of voltage sag can be determined by using various methods. Most existing power quality monitors obtain the sag magnitude from the rms voltages. The rms value voltage sag is calculated from the sampled time domain is given as

$$
\operatorname{Vrms}=\frac{1}{\mathrm{~N}} \sum_{\mathrm{i}=1}^{\mathrm{N}} \mathrm{v}_{\mathrm{i}}^{2}
$$

where vi is the voltage sample in time domain, $\mathrm{N}$ is the number of samples per cycle taken in a window. One cycle or half cycle window can be used for calculating rms voltage. The rms voltage after the voltage sag is slightly lower than before the sag. Fundamental voltage component, peak voltage, and missing voltage methods can be used for magnitude calculation of voltage sag.

Table 2. Basic types of symmetrical and unsymmetrical voltage sags

\begin{tabular}{|c|c|c|}
\hline $\begin{array}{l}\text { Sag } \\
\text { Type }\end{array}$ & $\begin{array}{c}\text { Phasor Diagram } \\
\text { (Solid Lines During Fault) }\end{array}$ & Phase to Neutral Voltages \\
\hline \multicolumn{3}{|c|}{ Symmetrical voltage sag } \\
\hline $\begin{array}{l}\text { Type } \\
\text { A }\end{array}$ & $\stackrel{\mathrm{Va}}{\longrightarrow}$ & $\begin{array}{l}\overline{\mathrm{V}}_{\mathrm{a}}=\mathrm{V} \\
\overline{\mathrm{V}}_{\mathrm{b}}=-\frac{1}{2} \mathrm{~V}-\mathrm{j} \frac{\sqrt{3}}{2} \mathrm{~V} \\
\overline{\mathrm{V}}_{\mathrm{c}}=-\frac{1}{2} \mathrm{~V}+\mathrm{j} \frac{\sqrt{3}}{2} \mathrm{~V}\end{array}$ \\
\hline \multicolumn{3}{|c|}{ Unsymmetrical voltage sag } \\
\hline
\end{tabular}

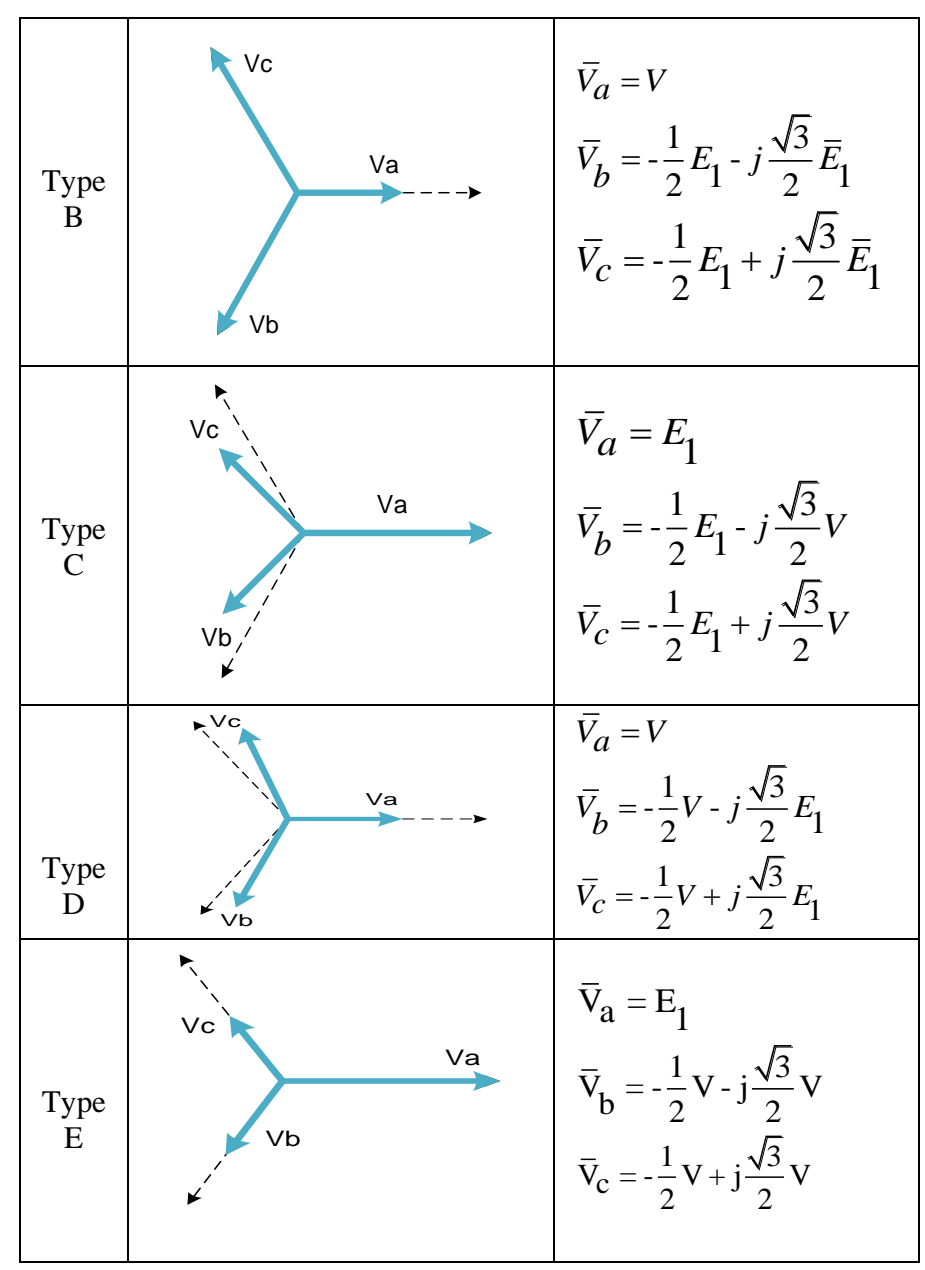

The voltage sag duration: It is the period of time in which the voltage is lower than a stated limit, shown in fig. 1. According to [3], sag magnitudes range from $10 \%$ to $90 \%$ of nominal voltage and sag durations from half-cycle to $1 \mathrm{~min}$.

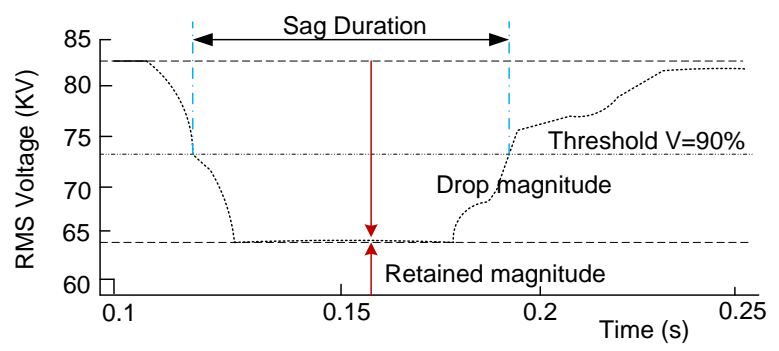

Fig. 3. Voltage sag magnitude and duration characteristics

Generally, sag duration is less than 1 second. The duration of voltage sag is measured from the moment the rms voltage drops to below $0.9 \mathrm{pu}$ of nominal voltage to when it rises to above $0.9 \mathrm{pu}$ of nominal voltage. When a sliding window is used to calculate the rms voltage as a function of time, erroneous voltage sag duration might result [8]. Several methods have been proposed to measure voltage sag initiation and voltage recovery more accurately. These methods also give a more accurate value of voltage sag duration [9-10].

The duration of voltage sag is mainly determined by the fault clearing time by various protective devices, but it may be longer than the fault clearing time. When the fault is cleared the voltage does not recover immediately. 
Phase angle jump: The change in phase angle is referred to as the phase-angle jump associated with the voltage sag. The phase angle jump is visible in time domain plot of the voltage sag as a shift in voltage zero crossing between the pre event and the during event voltage. The phase angle jump is the difference between the actual voltage angle and the reference voltage angle. The reference angle follows a straight line because it rotates with constant speed. The actual angle coincides with the reference angle until the starting of the event. After this the actual angle diverges from the reference angle causing the phase angle jump. After the event occurs, the actual angle may not coincide with the reference one. The phase angle of the voltage contains additional information on the cause of the event.

The phase angle jumps during three phase faults are due to the difference in X/R ratio the source and the feeder. The second cause of phase angle jumps is the transformation of sags to lower voltage levels. By comparing the phase angle of the voltage during the voltage sag with the phase angle of the voltage before the voltage sag, the phase angle jump can be measured. The phase angle of the voltage can be obtained from the voltage zero crossing or from the phase of fundamental component of the voltage. Phase angle jump can be determined using fundamental component of voltage. The complex fundamental voltage component as a function of time may be calculated as

$$
V_{\text {fund }^{(t)}}=\frac{2}{N} \int_{t-T}^{t} v(\tau) e^{i \omega_{0} \tau} d \tau
$$

where $\omega o=\frac{2 \pi}{T}$ and $T$ is one cycle of the fundamental frequency.

The absolute value of this complex voltage is the voltage magnitude as a function of time; its argument can be used to obtain the phase angle jump. This method assumes that there is no dc voltage component present. Due to a fault in power systems, there will be a change in voltage at a certain point, not only in magnitude but also in phase angle. However, both IEEE and IEC standards have not yet provided a unique definition of the change in phase angle.

\section{VOLTAGE SAG DETECTION TECHNIQUES}

Various voltage sag detection techniques are documented in literature [7-8], [11-13].The importance of voltage sag detection techniques is to provide a real-time and reliable detection of disturbances for their further analysis [8]. The root mean square voltage value is applied most broadly in power quality monitoring. According to [11] the one cycle rms voltage shall be compared with a threshold every half cycle, for the detection of voltage sag. Once an event is detected, its indices are calculated and stored. The rms method represents one cycle historical average value, not instantaneous value which may lead to long detection time when voltage sag has occurred [12]. Also, another drawback of rms is its dependency on the size of sample window and on the time interval for updating the values. The window size can be selected from a half cycle of the power system frequency upto any multiple of half cycles. A sudden change in magnitude of a voltage supply is not immediately detected using the rms calculation, it being a necessary that the new value of the voltage after the changes is entirely within the sampling window to obtain its correct magnitude. This method is simple and easy to implement but it does not give information about the phase angle of voltage during the event or the point on the wave where the event begins. The voltage sag can be detected by peak voltage method [13]. Its significant advantage of over other methods is that it needs only single-phase values. The comparison verifies the method's ability in detecting the input signal's peak value in the least possible time. The detection took at least a quarter of a cycle.

Voltage sag can also be detected using missing voltage technique. In missing voltage technique, the missing voltage can be obtained by subtracting the actual instantaneous value from the desired instantaneous voltage. The start and end of voltage sags can be determined by missing voltage [12]. Furthermore, it gives a more accurate indication of the duration of the event.

The comparison of different voltage sag detection techniques is presented in [14].

To overcoming the problem of delay in detection time shown by other detection techniques, phase angle jump is used for voltage sag detection.

\section{PMU BASED VOLTAGE DETECTION METHOD}

Phasor Measurement Units (PMUs) are next generation measuring devices for future power system. PMU based on GPS technique is widely used to monitor the state of a power system. These devices are capable of directly measuring frequency, voltage and current waveforms along with phase angle differences at high sampling rates and accuracies. Modern PMUs should have some other features, like system frequency measurement, measurement of power components, power quality related indicators like local frequency and rate of change of frequency, harmonic, etc., and monitoring of the status of substation apparatus. The basic operation needed for PMUs to work is described in [16]. The basic PMU block diagram is shown in fig. 4.

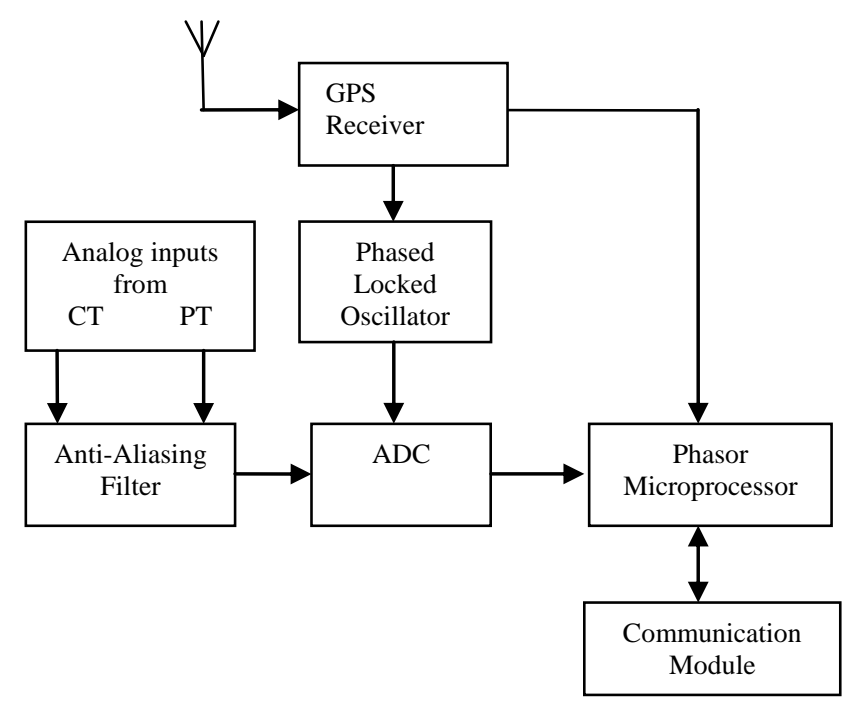

Fig. 4. Basic PMU block diagram

PMU calculate phasors of voltage and current from sampled data continuously as per standard. All this information should be synchronized with a high accuracy to a common reference time provided by GPS.

A pure sinusoidal waveform can be represented by a unique complex number known as a phasor. A phasor is defined as a vector representation of the magnitude and phase angle of an $\mathrm{AC}$ voltage waveform. 
Consider a sinusoidal signal $\mathrm{x}(\mathrm{t})$

$$
\mathbf{x}(\mathbf{t})=\mathrm{Xm} \cos (\omega t+\varphi)
$$

where $\mathrm{Xm}$ is the signal magnitude, $\omega=2 \pi f$, where $\mathrm{f}$ is instantaneous frequency and $\varphi$ is the initial phase of the signal, its synchrophasor representation is

$$
\begin{gathered}
X=\left(\frac{X m}{\sqrt{2}}\right) e^{j \varphi} \\
X=(X m / \sqrt{2})(\cos (\varphi+j \sin (\varphi) \\
X=X r+j X i
\end{gathered}
$$

where $\mathrm{Xr}$ and $\mathrm{Xi}$ are real and imaginary components of the complex phasor representation, $(\mathrm{Xm} / \sqrt{ } 2)$ is the RMS value of the signal and $\phi$ is its instantaneous phase angle relative to a cosine function at nominal system frequency synchronized to UTC. The phase $\phi$ is defined to be $0^{\circ}$ when the maximum of $\mathrm{x}(\mathrm{t})$ occurs at the UTC time instant, and $90^{\circ}$ when the negative zero crossing occurs at the UTC time instant. The phasor angle jump could be positive or negative which means that the phase angle increases or decreasing during fault [17]

The various applications of PMUs are documented in [17-20]. Through the phasor measurements taken at different locations at the same time, the operators could obtain a more accurate value of angle difference between different places which is useful for power system monitoring, supervision, and control. Real time monitoring using PMUs helps to detect changes in voltage magnitude, voltage angle, frequency or power flow as soon as they occur. So, the information provided by PMU can be used to the power quality monitoring. In [21] characterization of sag from both data sources are compared by using a set of actual measurements obtained from a power quality monitor and from a PMU, indicating advantages and disadvantages of each device. We can measure frequency and rate of change of frequency through PMU. Change in frequency can reflect the change in impedance of power system component

For given sinusoidal signal $\mathrm{X}(\mathrm{t})=\mathrm{Xm} \cos (\psi \mathrm{t})$

The frequency and rate of change of frequency is obtained as per synchrophasor standard [22]

$$
f(t)=\frac{1}{2} \frac{d \psi}{d t}
$$

and

$$
\text { ROCOF }=\frac{d f(t)}{d t}
$$

\section{SIMULATION RESULTS AND DISCUSSIONS}

In this paper, single line to ground fault (SLGF) of three phase of power supply is considered and simulated using MATLAB for detection and monitoring of voltage sag. The block diagram of the model is shown in Fig. 5.

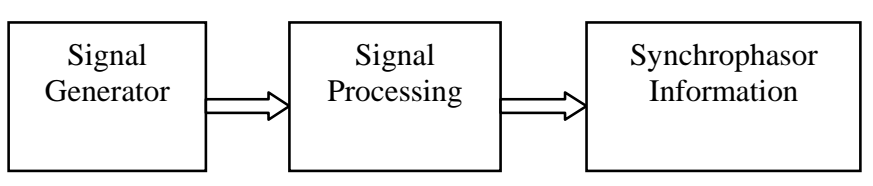

Fig. 5. Block diagram of the simulated model

The voltage sag is simulated by varying the magnitude, duration and phase angle jump. The magnitude may be reduced to a low value and it has been reduced to $80 \%$ so as to have a unbalanced sag of $20 \%$, appeared on phase 'a' of three phase power supply. Sag of $80 \%$ is simulated in phase ' $a$ ' which starts at time 0.2 second and last up to 0.5 second. The phase angle jump depends on the point on wave; however, it is taken as 4 degree phase angle jump. The duration of the sag is taken as 0.5 seconds.

Next is the processing block, wherein, the DFT is performed on the generated signal. This yields the magnitude and phase angle of the voltage at power frequency. The positive sequence component of the voltage (Vpositive) and phase angle jump are thus derived.

Further, the rate of change of frequency is computed (ROCOF) using expression (8). The variation of positive sequence voltage component Vpositive, rate of change of frequency, and phase angle jump is shown in fig. 6 . The phase angle jump of 4 degree during the fault has been observed. The findings demonstrate the effectiveness of the proposed method of detecting the voltage sag using PMU.

\section{CONCLUSION}

The conventional method of detecting voltage sag does not take into account all the characteristics like phase angle jump. The main feature of the PMU .i.e. information of magnitude of the positive sequence component, phase angle jump, are exploited in this work which may lead to fast detection of voltage sag. 


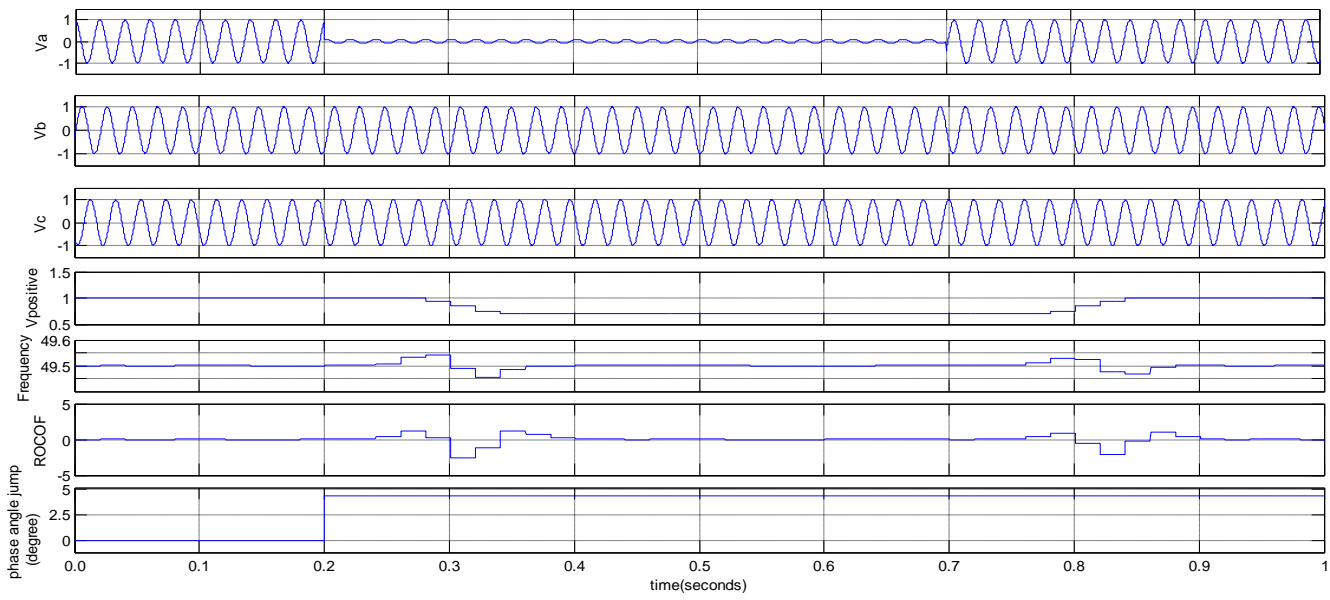

Fig. 6. Variation of Phase Voltage ( $\mathrm{Va}, \mathrm{Vb}, \mathrm{Vc})$, positive sequence voltage (Vpositive), frequency,rate of change of frequency (ROCOF) and phase angle jump with time.

\section{REFERENCES}

[1] Bollen, MHJ, Understanding Power Quality Problems: Voltage Sags and Interruptions, Series on Power Engineering, New York, IEEE Press, 2000.

[2] Heydt, G.T., Electric Power Quality, Stars in a Circle, 1994.

[3] IEEE Standard-1159-1995, IEEE Standard for Recommended Practices on Monitoring Electric Power Quality, 1995.

[4] IEC standard 61000-4-30, 2001, Electromagnetic Compatibility (EMC). Part 4-30: Testing and Measurement Techniques-Power Quality Measurement Methods.

[5] Lamoree, J. et al. "Voltage Sags Analysis Case Studies," IEEE Transactions on Industry Applications, vol. 30, no 4, July/August 1994.

[6] McGranaghan, MF et al., "Voltage Sags in Industrial Systems," IEEE Transactions on Industry Applications, vol. 29, no. 2, pp.397-403, 1993.

[7] Douglas, J, "Power Quality Solutions", IEEE Power Engineering Review, March 1994, pp. 3-7.

[8] Ding Ning et al,"Voltage Sag Disturbance Detection Based on RMS Voltage Method," Asia-Pacific Power and Energy Engineering Conference, APPEEC 2009, pp.1-4, 2009.

[9] Poisson, O et al., "Detection and Measurement of Power Quality Disturbances using Wavelet Transform," 8th International Conference Harmonics and Quality of Power, Athens, Greece, pp. 1125-1130, 1998.

[10] Naidoo, R and Pillay P, "A New Method of Voltage Sag and Swell Detection," IEEE Transactions on Power Delivery, vol. 22, no. 2, pp. 1056-1063, 2007.

[11] Wang, ZQ, et al., "Comparisons on Ways of Magnitude Characterization of Power Quality Disturbances," Large Engineering Systems Conference on Power Engineering, LESCOPE 02, 2002, pp. $178-183$.

[12] Ding, K at. el., "A Novel Detection Method for Voltage Sags," 2nd International Conference on
Power Electronics Systems and Applications, ICPESA '06, Hong Kong, Nov. 2006, pp.250-255.

[13] Tunaboylu, N.S, et al., "Voltage Disturbance Evaluation Using the Missing Voltage Technique," International Conference on Harmonics and Quality of Power, Athens, vol. 1, pp. 577-582, 14-18 Oct 1998.

[14] Alonso, M et al., "Comparison of Different Voltage Dip Detection Techniques," International Conference on Renewable Energies and Power Quality (ICREPQ'09), Valencia (Spain), 15th to 17th April, 2009.

[15] Phadke, AG and Thorp, JS, "Synchronized Phasor Measurements and Their Applications", New York: Springer, 2008.

[16] Novosel, D et al., "Benefits of Synchronized Measurement Technology for Power-grid Applications," 40th Annual Hawaii International Conference on System Sciences, HICSS 2007, 3-6 Jan. 2007, Walkoloa, Hawaii, pp. 118-125.

[17] Bindeshwar Singh, et al., "Applications of Phasor Measurement Units (PMUs) in Electric Power System Networks incorporated with FACTS Controllers," International Journal of Engineering, Science and Technology, vol. 3, no. 3, pp. 64-82, 2011.

[18] Ree, J.D L et al. "Synchronized Phasor Measurement Applications in Power Systems," IEEE Transactions on Smart Grid, vol. 1, no. 1, pp. 20-27, 2010.

[19] Begovic, $\mathrm{M}$ et al., "Issues Related to the Implementation of Synchrophasor Measurements," Proceedings of the 41st Hawaii International Conference on System Sciences, Annual, Waikoloa, HI, 7-10 Jan. 2008.

[20] Roberto C. LEBORGNE and Daniel KARLSSON, "Phasor Based Voltage Sag Monitoring and Characterization," 18th International Conference and Exhibition on Electricity Distribution, Turin, Italy, 6-9 June 2005, pp. 1-4.

[21] IEEE Standard 1344-1995, IEEE Standard for Synchrophasor Measurements for Power Systems, 1995. 